\title{
Skeletal muscle microalterations in patients carrying Malignant Hyperthermia-related mutations of the e-c coupling machinery
}

\author{
Manuela Lavorato (1), Pawan K Gupta (2), Philip M Hopkins (2), Clara Franzini- \\ Armstrong (1) \\ (1) Department of Cell and Developmental Biology, University of Pennsylvania School of \\ Medicine, Philadelphia PA, USA; (2) Malignant Hyperthermia Unit, Leeds Institute of \\ Biomedical and Clinical Sciences, St James's University Hospital, Leeds, UK.
}

This article is distributed under the terms of the Creative Commons Attribution Noncommercial License (CC BY-NC 4.0) which permits any noncommercial use, distribution, and reproduction in any medium, provided the original author(s) and source are credited.

\begin{abstract}
We have compared the ultrastructure of skeletal muscle biopsies from patients that have survived a [Malignant Hyperthermia, MH] episode and siblings that test positive for $\mathrm{MH}$ susceptibility with those from siblings that tested negatives. The aim is to establish whether life long exposure to the MH-related mutation effects may result in subtle abnormalities even in the absence of active episodes and/or clinically detectable deficiencies. Although a specific ultrastructural signature for $\mathrm{MH}$ mutants cannot be demonstrated, an $\mathrm{MH}$ related pattern of minor alterations does exist. These include the tendency for micro damage to the contractile apparatus and a higher than normal level of mitochondrial abnormalities.
\end{abstract}

Key Words: Malignant hyperthermia, Ultrastructure, Skeletal Muscle, Mitochondria

Eur J Transl Myol 26 (4): 323-332

Malignant hyperthermia (MH) is a life-threatening pharmacogenetic disorder of skeletal muscle affecting as many as 1:2,000 individuals. MH is mostly linked to mutations in type 1 ryanodine receptors (RyR1) that renders the channel susceptible to leak. ${ }^{1,2}$ Other mutations of the excitation-contraction coupling apparatus, most notably $\mathrm{Ca}_{\mathrm{v}} 1.1$ are also causative, but with lower prevalence..$^{3-7}$ The great majority of $\mathrm{MH}$ susceptible patients remain subclinical until challenged by halogenated volatile anaesthetics or depolarizing neuromuscular blockers that trigger a fulminating $\mathrm{MH}$ episode. The episodes are due to unregulated calcium release from the sarcoplasmic reticulum (SR) via RyR1 leading to accelerated cellular metabolism, hyperthermia and sustained contractile activity that results in severe muscle damage (rhabdomyolysis). The reaction is likely to be fatal if not promptly treated. $\mathrm{MH}$ susceptibility is confirmed in probands (patients that had a fulminant episode) and is established in their relatives in vitro pharmacological challenge tests of excised skeletal muscle samples. ${ }^{8}$ The Leeds $\mathrm{MH}$ Investigation Unit is the United Kingdom national centre for the diagnosis of $\mathrm{MH}$ and thus it has the opportunity of diagnosing and genetically testing a large number of patients using high high-throughput genomic DNA sequencing to identify novel MH related mutations in CACNAIS as well as RYRl. ${ }^{9}$
We have examined the ultrastructure of skeletal muscle biopsies obtained from patients who have had a $\mathrm{MH}$ reaction and from relatives whose muscles had either a positive or negative response to in vitro tests for $\mathrm{MH}$ susceptibility. Our interest is in detecting whether chronic alterations in muscle ultrastructure accompany the prolonged presence of mutations inducing $\mathrm{MH}$ susceptibility. We show that although a specific ultrastructural signature for $\mathrm{MH}$ mutants cannot be demonstrated, an $\mathrm{MH}$ related pattern of minor alterations does exist.

\section{Material and Methods}

\section{The biopsies}

Muscle biopsies were obtained from patients that had a previous reaction (index cases) or from relatives who were undergoing diagnostic testing because of a family history. For all index cases, there was at least a four month interval between the clinical episode and the biopsy. Open biopsies were performed on the motor point of vastus medialis at St James's University Hospital in Leeds. MH susceptibility status was assigned using the in vitro contracture test protocol of the European MH Group. ${ }^{8}$ For the EM specimens a muscle bundle containing 15 to 30 fibres was stabilized in situ using a double clamp and then excised. Fixation was by immersion in $3 \%$ glutaraldehyde in $0.1 \mathrm{M}$ phosphate buffer and the bundles were kept in the 


\section{Skeletal muscle in Malignant Hyperthermia patients}

Eur J Transl Myol 26 (4): 323-332
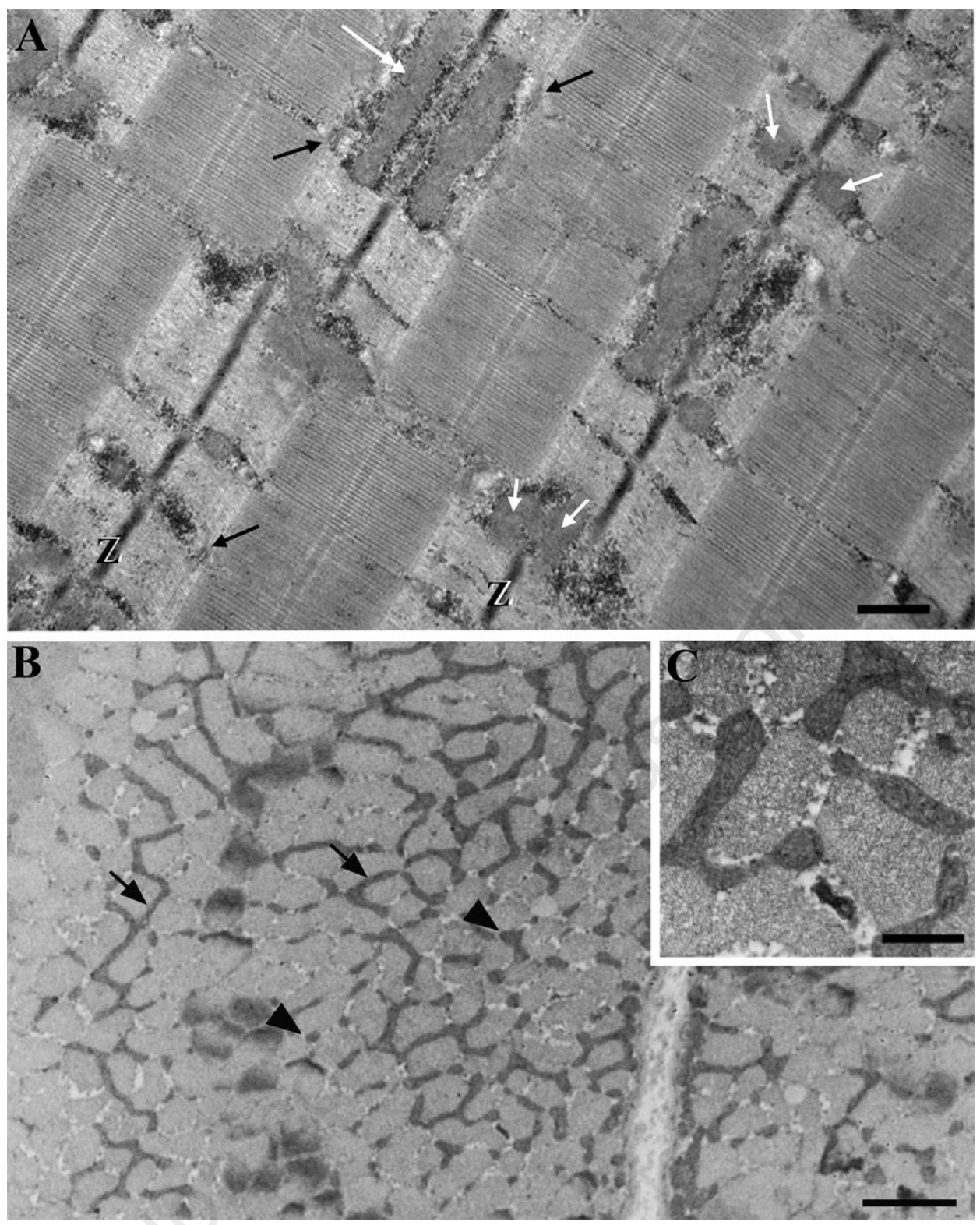

Fig 1. Ideal structural organization of normal fast skeletal muscle fibres from MH-patients. A) Longitudinal section. The biopsy was fixed close to resting length, thin filaments overlap the lateral $1 / 3$ of the A band. $Z$ lines $(Z)$ are narrow $(\sim 60 \mathrm{~nm})$. Triads (black arrows) are located in some but not all the intermyofibrillar spaces (IMF) near the edges of the A band. Mitochondria appear either as twin round or slightly elongated profiles on either side of the $Z$ lines (white arrows) or as long profiles when tangentially sectioned (double white arrow). B) Cross section of MHfibres show elongated mitochondria (arrows) surrounding myofibrils with lengths of up to several microns and some branching. In other areas of the same fibres shorter mitochondria segments are present (arrowheads). The proportion of elongated mitochondria versus short segments varies greatly in $\mathrm{MH}$-fibres (Table 1). C) Shorter mitochondria are often aligned and sometimes apparently connected to each other, presumably indicating either fission or fusion events. Bars = A, C: $0.5 \mu \mathrm{m} ; \mathrm{B}: 2 \mu \mathrm{m}$.

fixative at $4 \mathrm{C}$ for various periods of time (up to 42 weeks) until shipped to the USA for EM. Parallel specimens were sent for routine histology, which did not report any obvious alterations.

Two sets of biopsies were shipped to the EM laboratory. The first set included two biopsies from relatives that tested negative, two from index patients and three from relatives that tested positive. A second set of 10 biopsies from either index or confirmed $\mathrm{MH}$ susceptible patients were individually paired with biopsies from age and sex matched $\mathrm{MH}$ negative patients (in one case the two were 12 and 14 years old sisters). The biopsies were 


\section{Skeletal muscle in Malignant Hyperthermia patients}

Eur J Transl Myol 26 (4): 323-332
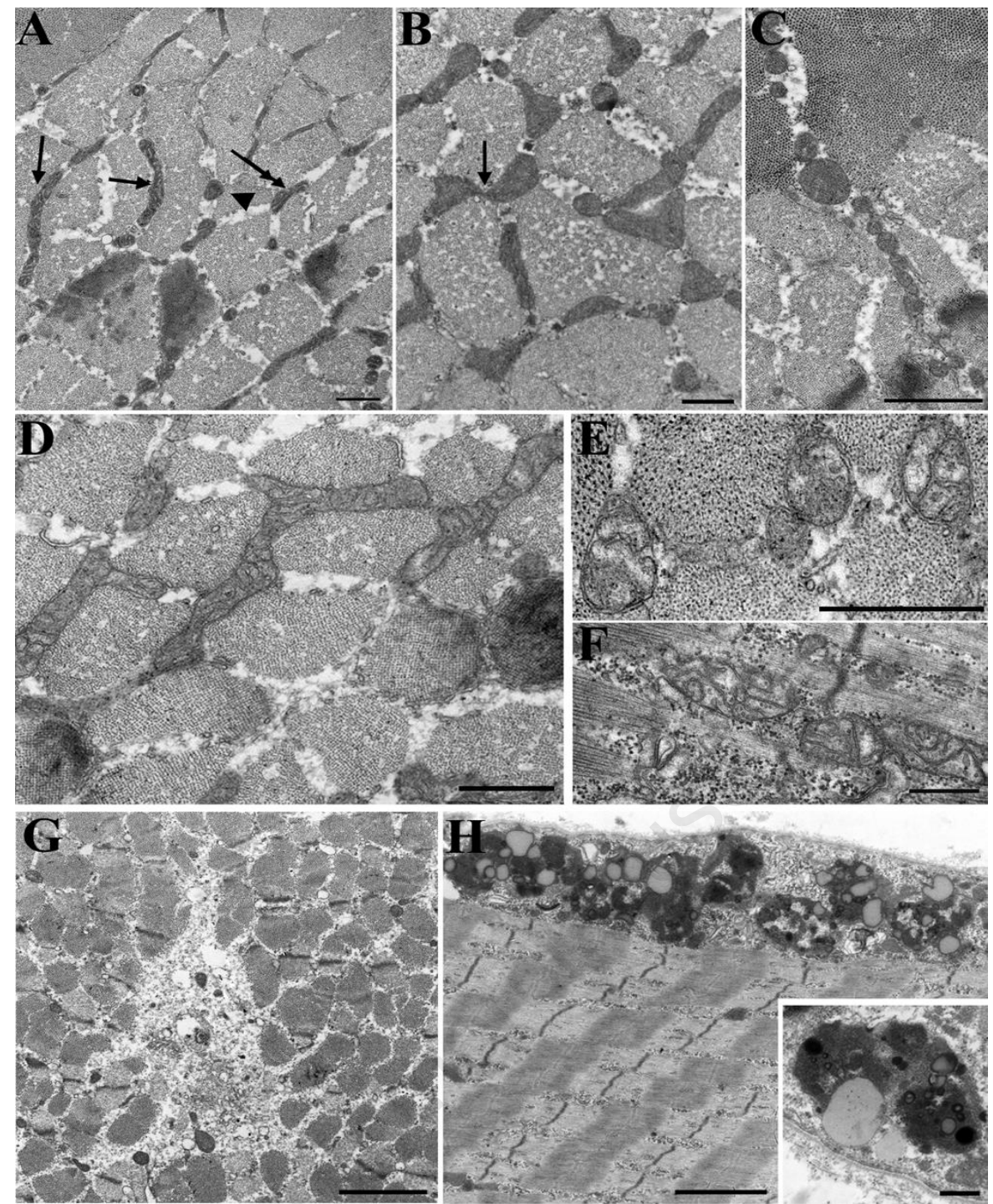

Fig 2. Shape and inner architecture of mitochondria are quite variable in $M H+$ fibers: evidence of some breakdown. A) Mitochondria in $\mathrm{MH}+$ biopsies are mostly located in the I band as in $\mathrm{MH}$-, but the elongated forms (arrows) are limited in length and in distribution. Short mitochondria segments (double arrow) and round profiles (arrowhead) are more frequent (Table 2). B) Shorter mitochondria are often aligned and sometimes apparently connected to each other (see also Fig. 2B). C) Very small round mitochondria forming a "chain" in the IM space are indicative of fragmentation. Such events are fairly frequent in $M H+$ fibres (Table 2). D-F) Mitochondrial internal architecture is altered in the majority of $\mathrm{MH}+$ biopsies. Mild reduction of matrix density and cristae disarrangement $(D)$ is detected in the majority of MH+ fibers. Highly disarranged cristae and almost empty matrix (E, F) are less frequent. G) Small unstructured regions containing some cellular debris, indicative of local degeneration are found in both $\mathrm{MH}$ - and $\mathrm{MH}+$. The example is from an $\mathrm{MH}+$ biopsy. $\mathrm{H}$ ) Chain of lysosomes and lypofucsin granules at the periphery of the fibre and a detail in the inset. These represent residual bodies remaining after degradation of cytoplasmic components. The two examples are from $M H$ - biopsies, but they are also frequent in $M H+$. Bars = A,B, D-F: $0.5 \mu \mathrm{m} ; C: 1 \mu \mathrm{m} ; \mathrm{G}, \mathrm{H}: 2 \mu \mathrm{m}$, insert $0.5 \mu \mathrm{m}$.

coded and shipped for blind examination by EM and later classified as in tables 1 and 2 . The following mutations were identified (biopsy \# in parenthesis): (C6S) RYR1 A2350; (B4E) RYR1 R177C; (F12) CACNA1 R1086S; (K22) RYR1 G2434R; (J20) RYR1 T4826I; (C7E) RYR1 A2350T; (E10) RYR1b R2458H; (L24) RYR1R2454RH; (G14) RYR1 E3004K.

\section{Electron microscopy}

For thin section EM the biopsies were post fixed either in $2 \% \mathrm{OsO}_{4}$ in $0.1 \mathrm{M}$ cacodylate buffer or in the same solution with addition of $0.8 \%$ of $\mathrm{K}_{3} \mathrm{Fe}(\mathrm{CN})_{6}$ for $1 \mathrm{~h}$ at 4 ${ }^{\circ} \mathrm{C}$, en-bloc stained with a saturated aqueous uranyl acetate and embedded in epon. Thin sections (60-70 $\mathrm{nm})$ were cut with ultra-microtome Leica Ultracut UCT 


\section{Skeletal muscle in Malignant Hyperthermia patients}

Eur J Transl Myol 26 (4): 323-332

Table 1. Triads, mitochondria, $Z$ line streaming and contractures in muscles from relatives that tested negative for MH susceptibility.

\begin{tabular}{|c|c|c|c|c|c|c|c|c|}
\hline \multirow[t]{2}{*}{ Biopsy } & \multirow{2}{*}{$\begin{array}{l}\text { Age \# } \\
\text { sex }\end{array}$} & \multirow[t]{2}{*}{ Family } & \multirow{2}{*}{$\begin{array}{l}\text { Triads/ } \\
\text { IMF } \\
\text { X 100* }\end{array}$} & \multicolumn{2}{|c|}{ Mitos/IMMitos shapes ** } & \multirow{2}{*}{$\begin{array}{l}\text { Mitos inner } \\
\text { architecture } * * *\end{array}$} & \multicolumn{2}{|c|}{$\begin{array}{ll}\mathrm{Z} & \text { line } \\
\end{array}$} \\
\hline & & & & $\begin{array}{l}\mathbf{F} \\
\mathbf{X} 100 *\end{array}$ & & & $\begin{array}{l}\text { streaming } \\
\text { No/fibers } \\
\text { *,\#\# }\end{array}$ & $\begin{array}{l}\text { No/fibers } \\
*, \# \#\end{array}$ \\
\hline D9 & $12, \mathrm{~F}$ & Relative & $\begin{array}{l}46 \pm 12 \\
(10)\end{array}$ & $\begin{array}{l}30 \pm 18 \\
(10)\end{array}$ & $\begin{array}{l}\text { Variable. Few } \\
\text { elongated } \\
(10)\end{array}$ & $\begin{array}{l}\text { Very empty } \\
\text { matrix, variable } \\
\text { cristae }(20)\end{array}$ & & \\
\hline B5N & $45, \mathrm{~F}$ & Relative & $\begin{array}{l}42 \pm 14 \\
(9)\end{array}$ & $\begin{array}{l}44 \pm 9 \\
(9)\end{array}$ & $\begin{array}{l}\text { Variable, many } \\
\text { elongated (8) }\end{array}$ & $\begin{array}{l}\text { Variable cristae } \\
(17)\end{array}$ & & \\
\hline F 13 & $52, \mathrm{M}$ & Relative & $\begin{array}{l}35 \pm 15 \\
(8)\end{array}$ & $\begin{array}{l}48 \pm 24 \\
(8)\end{array}$ & $\begin{array}{ll}\text { Variable, many } \\
\text { elongated } \\
\text { Clustering } \\
(16)\end{array}$ & $\begin{array}{l}\text { Slightly variable } \\
\text { cristae (24) }\end{array}$ & & \\
\hline I19 & $55, \mathrm{~F}$ & Relative & $\begin{array}{l}44 \pm 13 \\
(10)\end{array}$ & $\begin{array}{l}32 \pm 21 \\
(10)\end{array}$ & $\begin{array}{l}\text { Variable but } \\
\text { scarce overall } \\
(14)\end{array}$ & & & $\begin{array}{l}+ \\
3 / 10\end{array}$ \\
\hline A3N & $56, \mathrm{~F}$ & Relative & $\begin{array}{l}55 \pm 11 \\
(13)\end{array}$ & $\begin{array}{l}43 \pm 17 \\
(13)\end{array}$ & $\begin{array}{l}\text { Elongated. One } \\
\text { type } 1 \text { fibre } \\
(8)\end{array}$ & & & \\
\hline K23 & $56, \mathrm{M}$ & Relative & $\$$ & $\$$ & $\begin{array}{l}\text { Few, variable } \\
\text { Some clustered } \\
(8)\end{array}$ & & & $1 / 10$ \\
\hline $\mathbf{J 2 1}$ & $57, \mathrm{M}$ & Relative & $\begin{array}{l}44 \\
(10)\end{array}$ & $\begin{array}{l}52 \\
(10)\end{array}$ & $\begin{array}{l}\text { Very long and } \\
\text { frequent } \\
(10)\end{array}$ & 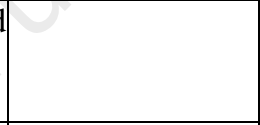 & & \\
\hline H17 & $64, \mathrm{M}$ & Relative & $\$$ & $\begin{array}{l}27 \\
(10)\end{array}$ & $\begin{array}{l}\text { Few, round } \\
\text { Clustering } \\
(10)\end{array}$ & & & $\begin{array}{l}+ \\
2 / 10\end{array}$ \\
\hline E11 & $68, F$ & Relative & $\begin{array}{l}44 \pm 11 \\
(10)\end{array}$ & $\begin{array}{l}30 \pm 22 \\
(10)\end{array}$ & $\begin{array}{l}\text { Few, round } \\
\text { Clustering } \\
(10)\end{array}$ & $\begin{array}{l}\text { Variable cristae } \\
(20)\end{array}$ & & \\
\hline $\mathbf{M 2 7}$ & $70, \mathrm{~F}$ & Relative & $\begin{array}{l}42 \pm 14 \\
(10)\end{array}$ & $\begin{array}{l}47 \pm 25 \\
(10)\end{array}$ & $\begin{array}{l}\text { Elongated } \\
\text { Variable } \\
\text { Clustering } \\
(15) \\
\end{array}$ & & $1 / 10$ & \\
\hline G15 & $71, \mathrm{M}$ & Relative & $\begin{array}{l}39 \pm 12 \\
(9)\end{array}$ & $\begin{array}{l}24 \pm 12 \\
(9)\end{array}$ & $\begin{array}{l}\text { Very variable } \\
(16)\end{array}$ & $\begin{array}{l}\text { Variable cristae } \\
(25)\end{array}$ & + & $\begin{array}{l}++ \\
4 / 9\end{array}$ \\
\hline
\end{tabular}

The numbers in parenthesis indicate the number of fibres used for collecting the data.

\# Age at biopsy in years; * See Methods. Data were obtained from longitudinal sections only; ** Obtained from cross sections only; *** Obtained from longitudinal and cross sections; \$ Counts of triad frequency were not obtained because the contrast of the images was very poor or the fibres were stretched too far; \#\# Crosses give a qualitative assessment of the alteration extent. Absence of cross indicates limited extent. The numbers indicate the frequency of occurrence of each alteration relative to the number of fiber views examined in both transverse and cross sections.

(Leica Microsystem, Austria) using a Diatome diamond knife (Diatome Ltd. Biel, Switzerland) and contrasted with lead acetate. Sections were examined in a Philips 410 EM (Philips Electron Optics, Mahwah, NJ). The images were digitally recorded with a Hamamatsu C4742-95 digital camera (Advanced Microscopy Techniques, Chazy, NY). Cross sections showed profiles of all fibres in the biopsy, and a smaller subset of the sample was present in each longitudinal section.

\section{Data analysis}

The frequency of triads and mitochondria was evaluated using six photographs for each sample, covering areas of $\sim 45 \mu^{2}$ and collected at randomly selected positions along 8-13 (median 10) longitudinally sectioned fibre segments. In each area the number of intermyofibrillar (IMF) spaces on either side of the $\mathrm{Z}$ lines and the numbers of triad and/or mitochondrial profiles were counted. The ratios of triads/IMF and 


\section{Skeletal muscle in Malignant Hyperthermia patients}

Eur J Transl Myol 26 (4): 323-332

Table 2. Triads, mitochondria, $\mathrm{Z}$ line streaming and contractures in muscles from index patients and from relatives that tested positive for MH susceptibility..

\begin{tabular}{|c|c|c|c|c|c|c|c|c|}
\hline Biopsy & $\begin{array}{l}\text { Age \# } \\
\text { sex }\end{array}$ & Family & $\begin{array}{l}\text { Triad/ } \\
\text { IMF } \\
\text { X 100* }\end{array}$ & $\begin{array}{l}\text { Mitos/ } \\
\text { IMF } \\
\text { X 100* }\end{array}$ & $\begin{array}{l}\text { Mitos } \\
\text { shapes } \\
* *\end{array}$ & $\begin{array}{c}\text { Mitos inner } \\
\text { Architecture } \\
*_{* *}\end{array}$ & $\begin{array}{l}\text { Z line } \\
\text { streaming } \\
\text { No/fibers } \\
\text { **, \#\# }\end{array}$ & $\begin{array}{l}\text { Contracture } \\
\mathbf{s} \\
\text { No/fibers } \\
* * \text {, \#\# }\end{array}$ \\
\hline D8 & $14 \mathrm{~F}$ & Relative & $\begin{array}{c}37 \pm 13 \\
(10)\end{array}$ & $\begin{array}{c}35 \pm 18 \\
(10)\end{array}$ & $\begin{array}{l}\text { All small and } \\
\text { Fragmented } \\
(12)\end{array}$ & $\begin{array}{l}\text { Clear matrix, variable } \\
\text { cristae (22) }\end{array}$ & $2 / 10$ & $\begin{array}{l}+ \\
1 / 10\end{array}$ \\
\hline C6S & $22 \mathrm{M}$ & $\begin{array}{l}\text { Index } \\
\text { case }\end{array}$ & $\begin{array}{c}38 \pm 11 \\
(10)\end{array}$ & $\begin{array}{l}31 \pm 9 \\
(10)\end{array}$ & $\begin{array}{l}\text { Various } \\
\text { or round } \\
(10) \\
\end{array}$ & $\begin{array}{l}\text { Clear matrix, variable } \\
\text { cristae (20) }\end{array}$ & $\begin{array}{l}+ \\
2 / 8\end{array}$ & \\
\hline A1E & $23 \mathrm{M}$ & $\begin{array}{l}\text { Index } \\
\text { case }\end{array}$ & $\begin{array}{c}34 \pm 9 \\
(13)\end{array}$ & $\begin{array}{c}36 \pm 18 \\
(13)\end{array}$ & $\begin{array}{l}\text { Variable } \\
\text { Few elongated } \\
(10)\end{array}$ & $\begin{array}{l}\text { Clear matrix, } \\
\text { variable cristae (23) }\end{array}$ & & 0 \\
\hline B4E & $47 \mathrm{~F}$ & Relative & $\begin{array}{c}47 \pm 10 \\
(14)\end{array}$ & $\begin{array}{c}37 \pm 19 \\
(14)\end{array}$ & $\begin{array}{l}\text { Variable } \\
\text { Few elongated } \\
(5)\end{array}$ & $\begin{array}{l}\text { Some clear matrix, } \\
\text { variable cristae (19) }\end{array}$ & $2 / 14$ & + \\
\hline F 12 & $53 \mathrm{M}$ & $\begin{array}{l}\text { Index } \\
\text { case \$ }\end{array}$ & $\begin{array}{c}37 \pm 17 \\
(9)\end{array}$ & $\begin{array}{c}35 \pm 24 \\
(9)\end{array}$ & $\begin{array}{l}\text { Variable } \\
\text { Few elongated } \\
(14)\end{array}$ & $\begin{array}{l}\text { Mito clusters, odd } \\
\text { shapes (23) }\end{array}$ & $\begin{array}{l}+ \\
3 / 8\end{array}$ & $\begin{array}{l}++ \\
5 / 8\end{array}$ \\
\hline A2S & $55 \mathrm{~F}$ & Relative & $\begin{array}{l}54 \pm 14 \\
(6)\end{array}$ & $\begin{array}{c}34 \pm 11 \\
(6)\end{array}$ & $\begin{array}{l}\text { Few, mostly } \\
\text { Round (10) }\end{array}$ & $\begin{array}{l}\text { Occasional clear } \\
\text { matrix,variable } \\
\text { cristae }(16)\end{array}$ & $\begin{array}{l}+ \\
3 / 5\end{array}$ & \\
\hline I18 & $55 \mathrm{~F}$ & Relative & $\begin{array}{c}29 \pm 12 \\
(7)\end{array}$ & $\begin{array}{c}35 \pm 20 \\
(7)\end{array}$ & $\begin{array}{l}\text { Fragmented } \\
(19)\end{array}$ & $\begin{array}{l}\text { Fragmented mitos, } \\
\text { Cristae OK (26) }\end{array}$ & $3 / 10$ & $\begin{array}{l}++ \\
2 / 10\end{array}$ \\
\hline K22 & $56 \mathrm{M}$ & $\begin{array}{l}\text { Index } \\
\text { case }\end{array}$ & $\begin{array}{c}19 \pm 12 \\
(10)\end{array}$ & $\begin{array}{c}20 \pm 14 \\
(10)\end{array}$ & $\begin{array}{l}\text { Few, round } \\
\text { (12) }\end{array}$ & $\begin{array}{l}\text { Some clear matrix, } \\
\text { variable cristae (22) }\end{array}$ & $7 / 10$ & $3 / 10$ \\
\hline $\mathbf{J 2 0}$ & $57 \mathrm{M}$ & Relative & $\begin{array}{c}27 \pm 14 \\
(8)\end{array}$ & $\begin{array}{c}39 \pm 17 \\
(8)\end{array}$ & $\begin{array}{l}\text { Variable } \\
\text { Few elongated } \\
(12)\end{array}$ & $\begin{array}{l}\text { Clear matrix, variable } \\
\text { cristae }(20)\end{array}$ & $2 / 10$ & $2 / 10$ \\
\hline$\overline{\text { C7E }}$ & $59 \mathrm{M}$ & Relative & $\begin{array}{c}54 \pm 11 \\
(15)\end{array}$ & $\begin{array}{c}46 \pm 20 \\
(15)\end{array}$ & \begin{tabular}{|l} 
Elongated \\
Numerous (5)
\end{tabular} & $\begin{array}{l}\text { Normal cristae } \\
(15)\end{array}$ & 0 & $\begin{array}{l}++ \\
1 / 14\end{array}$ \\
\hline H16 & $62 \mathrm{M}$ & Relative & $\begin{array}{c}30 \pm 14 \\
(10)\end{array}$ & $\begin{array}{c}38 \pm 17 \\
(10)\end{array}$ & $\begin{array}{l}\text { Mito clusters } \\
\text { Unusual } \\
\text { Variations(11) }\end{array}$ & Altered mitos (21) & $\begin{array}{l}++ \\
1 / 10\end{array}$ & 0 \\
\hline E10 & $68 \mathrm{M}$ & Relative & $\begin{array}{l}51 \pm 14 \\
(9)\end{array}$ & $\begin{array}{l}39 \pm 18 \\
(9)\end{array}$ & $\begin{array}{l}\text { Few, round } \\
\text { Few long mito } \\
\text { chains }(21)\end{array}$ & $\begin{array}{l}\text { Occasional clear } \\
\text { matrix,variable cristae } \\
(30)\end{array}$ & 0 & 0 \\
\hline M26 & $71 \mathrm{M}$ & $\begin{array}{l}\text { Index } \\
\text { case }\end{array}$ & $\begin{array}{c}17 \pm 10 \\
(6)\end{array}$ & $\begin{array}{c}38 \pm 21 \\
(6)\end{array}$ & $\begin{array}{l}\text { Variable } \\
\text { Fragmented } \\
(10)\end{array}$ & $\begin{array}{l}\text { Normal cristae } \\
(16)\end{array}$ & $\begin{array}{l}+++ \\
5 / 6\end{array}$ & $2 / 6$ \\
\hline \begin{tabular}{|l|}
$\mathbf{L 2 4}$ \\
$(?)$
\end{tabular} & $74 \mathrm{M}$ & $\begin{array}{c}\text { Index } \\
\text { case }\end{array}$ & $? ? ?$ & $? ? ? ?$ & Very $\begin{array}{r}\text { few, } \\
\text { small }\end{array}$ & ????? & $3 / 17$ & $2 / 27$ \\
\hline G 14 & $79 \mathrm{M}$ & Relative & $\begin{array}{c}40 \pm 13 \\
(8)\end{array}$ & $\begin{array}{c}23 \pm 17 \\
(8)\end{array}$ & $\begin{array}{l}\text { Variable, many } \\
\text { Small (9) }\end{array}$ & $\begin{array}{l}\text { Clear matrix, variable } \\
\text { cristae (17) }\end{array}$ & 0 & 0 \\
\hline
\end{tabular}

The numbers in parenthesis indicate the number of file profiles used for collecting the data;

$\$$ Homozygous; \# Age at biopsy in years; * See Methods. Data were obtained from longitudinal sections only; ** Obtained from cross sections only; *** Obtained from longitudinal and cross sections

mitochondria/IFM are directly related to the frequency of connections between SR and T tubules (a variable that is related to the functional requirements for e-c coupling) and the frequency of mitochondria respectively (see Tables 1 and 2). A less precise estimate of the occurrence of infrequent alterations was based on their frequency relative to the number of EM views of sectioned fibre segment profiles. 


\section{Skeletal muscle in Malignant Hyperthermia patients}

Eur J Transl Myol 26 (4): 323-332
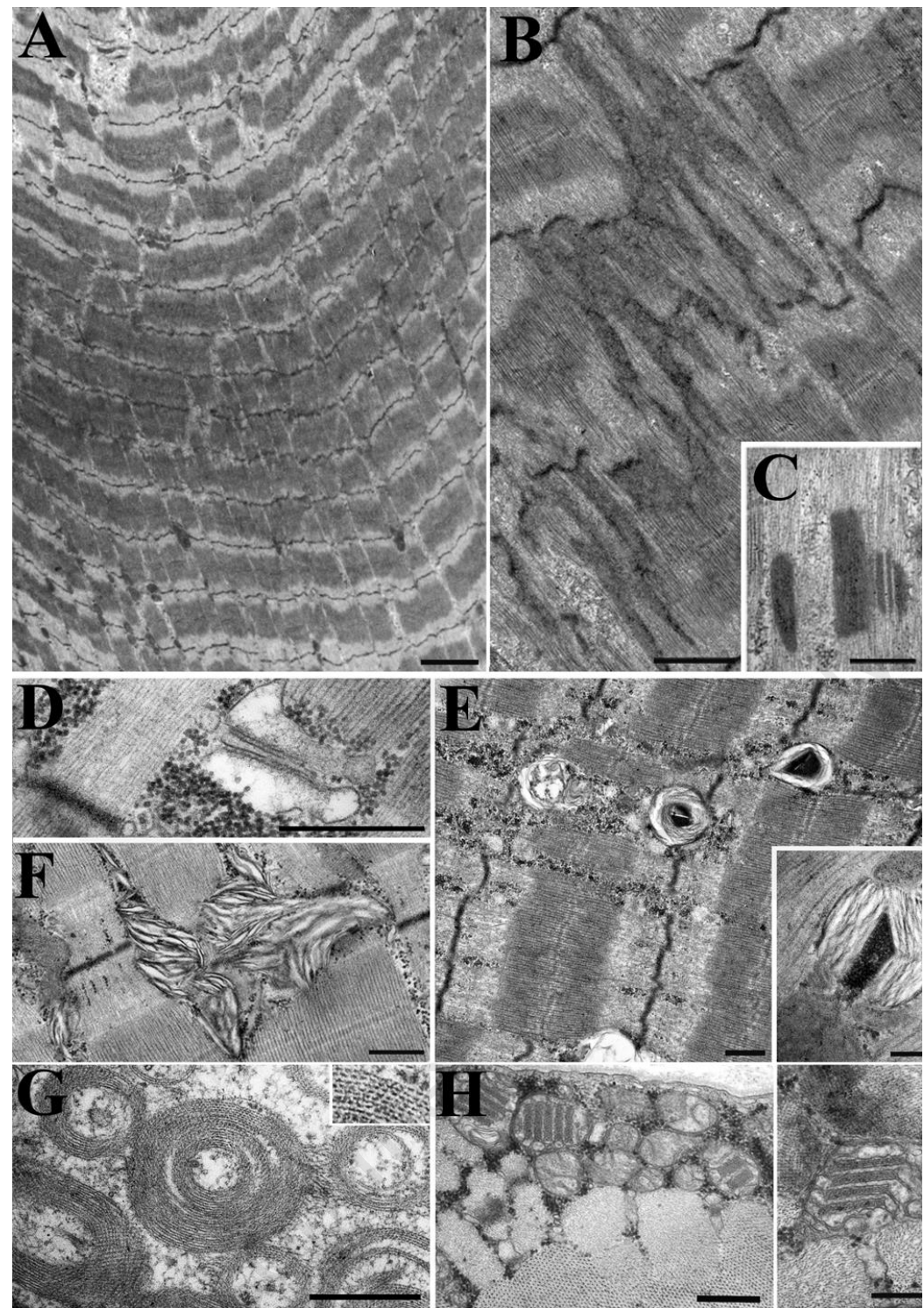

Fig 3. Contractures and $Z$ disk alterations are more common $M H+$ biopsies. A) Contractures are sharply delimited areas where sarcomeres are greatly shortened, flanked by regions where the sarcomeres are stretched. This is a classic example from a $\mathrm{MH}+$ fibre. Contractures are more frequent in $\mathrm{MH}+$ than in $\mathrm{MH}$-biopsies (Tables 1 and 2). $B)$ Large area of $Z$ line streaming in an $M H+$ fibre consisting of an apparent flow or extension of $Z$ line material longitudinally towards the A band, resulting in sarcomere disarray. $Z$ line streaming is more frequent and extensive in $M H+$ than $M H$ - biopsies. C) A classical nemaline rod was found, rarely, in a single index case for a CACNA1S mutation. Other alterations are less frequently observed and not related to $M H$ mutations. D) Dilated junctional SR with loss of CASQ content is observed in all cases. E, F) Myeloid structures are aggregations of stacked membranes with variable morphology probably due to final degradations of mitochondria, from $\mathrm{MH}$ - and $\mathrm{MH}+$ fibres respectively. G-H Two unusual structures: "concentric laminated bodies" (F) and crystalloid inclusions in mitochondria $(H)$ from $M H$ - fibres. They are also rarely seen in $M H+$ biopsies. Bars $=A, C: 2 \mu m ; B: 1 \mu m$. C-H: $0.5 \mu \mathrm{m}$.

\section{Results}

Each biopsy is made up of a bundle of fibre segments that do not extend for the whole muscle length, thus in the following description "fibre" means "fibre segment". All samples derive from individuals with a proven MH episode and their siblings. Biopsies that tested negative for $\mathrm{MH}$ susceptibility are indicated as $\mathrm{MH}-$ in tables and figure legends. $\mathrm{MH}+$ indicates affected and/or susceptible individuals.

Muscle fibres from all biopsies showed well-preserved ultra-structural details of sarcomeres, SR/T tubule/triads and mitochondria regardless of the length of storage period between the initial fixation in glutaraldehyde and 


\section{Skeletal muscle in Malignant Hyperthermia patients}

Eur J Transl Myol 26 (4): 323-332

the consequent post-fixation and embedding procedures. Only in two biopsies (not included in the analysis) myofibrils and myofilaments were well preserved, but contrast of the membrane systems had faded. In the great majority of biopsies the sarcomeres were quite stretched out, with very little or no thin/thick filaments overlap. This was uniquely the result of stretch imposed on the muscle bundles during the biopsy, before immobilizing them for fixation and it did not alter the ultrastructure except for elongating profiles in the longitudinal direction.

The $\mathrm{Z}$ line width was narrow $(50-80 \mathrm{~nm})$ in the great majority of fibers (Fig. 1A). Fibres with wide $\mathrm{Z}$ line (not shown) were present at very low frequency, i.e. 4-5 fibres in all biopsies observed and were not included in quantitative counts. A characteristic common to all fibres was the presence of numerous glycogen granules located between the myofibrils and also within the I band region (Fig. 1A). This is typical of human skeletal muscle. ${ }^{10}$ The anatomical location of the biopsy in the vastus medialis muscle, the high content of glycogen, ${ }^{11}$ the narrow $\mathrm{Z}$ lines, and the relatively low content of mitochondria, combined with the fact that the patientswere not active athletes, indicate that the majority of fibres within the biopsy bundles were of the fast IIX-, glycolytic-, fatigable-type, presumably expressing MHCIIX. ${ }^{11-13}$

A direct comparison between age and sex matched individual $\mathrm{MH}-$ and $\mathrm{MH}+$ biopsies did not reveal a compelling and/or consistent set of variables that could be used to identify a specific MH-related defect. However, a comparison of the entire $\mathrm{MH}+$ cohort with the complete $\mathrm{MH}$ - group did show clear and revealing trends. Thus the initial description and analysis of biopsies are given separately for the two groups.

Frequency and structure of triads and mitochondria vary between narrow limits in biopsies from $\mathrm{MH}$ negative patients

The content of triads and mitochondria were analyzed by morphometry. The triads were located in the intermyofibrillar spaces (IFM) at the border of the A band in fibres fixed at shorter lengths (Fig. 1A) and partially into the I band in stretched fibres. Table 1a shows a vertical view of age- and sex-related variations in the frequency of triads in the intermyofibrillar spaces from MH- individuals. The data were obtained by simply counting the numbers of intermyofibrillar spaces and those of triads within an area of longitudinal section (see methods). The frequency of triads gives a direct indication of the extent of junctional contacts between sarcoplasmic reticulum (SR) and $\mathrm{T}$ tubules. Additionally, given the observed apparent constancy of myofibrillar sizes, the ratio of organelle to spaces is directly proportional to the frequency of the organelle within the fibre volume. The sample size in Table 1 for $\mathrm{MH}$ negative muscles is fairly limited, but there was no obvious decline in the frequency of triads with aging.
The standard deviation for measurements in each biopsy is also fairly small, indicating limited variability between sampling areas.

Mitochondria showed a higher variability than triads both within and between fibres of the same individual and between different patients. In all cases sectioned mitochondria profiles were almost exclusively located at the I band level, but showed considerable variability in their shape, disposition and frequency (Table 1). The most obvious variations were readily apparent in cross sections of the fibres (Fig. 1B,C). In these views most of the $\mathrm{MH}$ - fibres showed areas that contained elongated mitochondria positioned along a transverse plane, running for the length of up to several microns, with branchings, and small variations in width (Fig. 1B). This category of mitochondria is indicated as "elongated" in Table 1. Even within the same fibre however the elongated mitochondria were mixed with others that were short or even round (Fig. 1B). Shorter mitochondria segments (indicated as "variable" in Table 1) were often located in brief rows between the myofibrils (Fig. 1C) suggesting an ongoing process of either fragmentation or fusion. In all muscles there are areas where mitochondria are basically spherical. In extreme cases (two biopsies) no mitochondria were elongated, but all were apparently spherical. Occurrence and frequencies of various mitochondrial shapes (elongated, variable and round) are roughly indicated in the "Mitos shape" column of Table 1.

Mitochondrial shapes correlate well with the frequency of mitochondrial profiles counted in longitudinal sections (Table 1). As expected the ratio of mitochondria profiles to IMF spaces is higher in fibres with a prevalence of elongated organelles and lower in fibres with round mitochondria. The high standard deviation of the frequency indicates a high variation of mitochondrial content in fibres of the same individual and indeed also in different areas of the same fibre. The average frequency does not show a clear trend with age. The internal mitochondrial architecture is also somewhat variable. In most cases, the architecture is standard with a dense matrix and well-ordered cristae (Fig. 1C). However, as indicated in the last column of Table 1, some biopsies show mitochondria with a less dense matrix and variable distributions of cristae. This variation is considerable more frequent in $\mathrm{MH}+$ samples.

Biopsies from $\mathrm{MH}+$ patients display a high variability in triad frequency, mitochondria structure and frequency

Fibres in MH+ biopsies, both from index cases and from relatives with a positive contracture test, showed a slight decrease in triad counts and larger variations between samples than MH- biopsies. The mean number of triads/IMF is $43 \pm 5$ (mean \pm SD) in $9 \mathrm{MH}$ - and $37 \pm 12$ in $14 \mathrm{MH}+$ (compare Tables 1 and 2). However, as in the case of $\mathrm{MH}$ - biopsies, the standard deviation of the 


\section{Skeletal muscle in Malignant Hyperthermia patients}

Eur J Transl Myol 26 (4): 323-332

mean for each biopsy is quite low indicating little variation in the content of triads between individual fibres of the same biopsy. Given the small number of samples available and the high variability in values, it is not surprising that statistical analysis did not indicate a significant difference in the average $\mathrm{MH}-\mathrm{MH}+$ frequencies $(p=0.13)$. It is noteworthy that the three $\mathrm{MH}+$ biopsies with the most elevated content of triads are from relatives, while those with the lowest levels are from index cases.

Mitochondria revealed significant differences between $\mathrm{MH}-$ and $\mathrm{MH}+$ cohorts. The first divergence is in the overall appearance and distribution of mitochondria. Very few $\mathrm{MH}+$ biopsies showed elongated mitochondria in cross sections at the level of the I band and, even where present, the long mitochondria occupied only small regions of the fibres (compare Fig. $2 \mathrm{~A}, \mathrm{MH}+$ with $1 \mathrm{~B}, \mathrm{MH}-)$. Most mitochondria were short with variable lengths (Fig. 2B) or round (Fig. 2C). Additionally there was apparent fragmentation, with the presence of numerous very small profiles, sometimes aligned in a row (Fig. 2C). As a result of the mitochondrial fragmentation into smaller organelles and of their overall scarcity, the mitochondria counts in Table 2 are consistently lower than in Table 1 . The only $\mathrm{MH}+$ biopsy with a mitochondrial/IMF count above 40 had a noticeable component of elongated organelles. There is no apparent correlation between mitochondria frequency and past occurrence of an $\mathrm{MH}$ episode: the biopsies with the lowest and highest mito/IMF numbers are from relatives.

A second striking variation between $\mathrm{MH}-$ and $\mathrm{MH}+$ mitochondria is in the internal architecture. The majority of $\mathrm{MH}+$ fibres presented mitochondria with a reduced density of the matrix content and an altered disposition of cristae (Fig. 2D-F). Although a minor effect in this direction was detected in a few of the $\mathrm{MH}$ biopsies (See Table 1), the alterations were much more substantial and consistently present in the $\mathrm{MH}+$ muscles (see Table 2 and Fig. 2).

Some, but not all, larger ultrastructural anomalies are more frequent in $\mathrm{MH}+$ fibres

All biopsies showed a variety of ultrastructural anomalies (besides those mentioned above) that involved small domains of the fibre and were present at low frequencies in a random distribution. Due to the low frequency of the events, it was not possible to obtain a precise morphometric analysis. The data are summarized by providing information on the frequency and extent of each type of pathology in relation to the number of thin section images of fibres examined in longitudinal and cross sections (Tables 1 and 2).

Two alterations, contractures and $\mathrm{Z}$ line streaming, indicative of current localized contractile activity and/or stress resulting from an earlier contraction were slightly elevated in $\mathrm{MH}+$ versus $\mathrm{MH}-$. "Contracture" indicates a localized area (often occupying a wide band across the fibre) where the sarcomeres are shortened in continuity with areas were the sarcomeres are greatly stretched (Fig. 3A). A contracture is indicative of an increase in cytoplasmic calcium ion concentration above contraction threshold, which is sustained over a period of time sufficient to allow immobilization by chemical fixation. Less than half of the MH- biopsies had a few small contractures, with a total of 10 in 39 fibres, while 11 of $15 \mathrm{MH}+$ biopsies displayed at least one, occasionally more contractures, and few of them were large (Tables 1 and 2). $\mathrm{Z}$ line streaming is a breakdown of the sarcomeric structure that starts with a longitudinal flow of $\mathrm{Z}$ line components and continues into highly altered $\mathrm{Z}$ lines and disarranged thin and thick filaments (Fig. 3B). Occurrences of $\mathrm{Z}$ line streaming are very rare in $\mathrm{MH}$ - biopsies (Table 1), but are present in almost all of the $\mathrm{MH}+$ samples and some involve fairly large areas (Table 2).

One case of $\mathrm{Z}$ line alteration of the type seen in nemaline myopathy was observed in an index case who carried a mutation in CACNAIS, which is less frequently implicated compared with RYRI (Fig. 3C). Since this is the only biopsy with a recognized mutation affecting the $\mathrm{Ca}_{\mathrm{V}} 1.1$ channel within the group examined, it is not possible to make any general inference on the association between CACNAIS mutations and $\mathrm{Z}$ line alterations.

The following indications of localized pathology show no positive correlation with $\mathrm{MH}$. Areas of degeneration, in which much of the ultrastructure is either disorganized or missing (Fig. 2G) are present in both $\mathrm{MH}-$ and $\mathrm{MH}+$ and the ratio of occurrences versus number of fibres examined is slightly higher in the former than in the latter (23/156 versus 26/231). Most of the damaged areas occupy a small region (Fig. 2G) and they are often located at the fibre periphery and/or near the nucleus.

A fairly common variation from normal morphology is a minor dilation of the junctional SR at the triads (Fig. 3D), with or without an apparent reduction in calsequestrin content. This alteration was present perhaps to a higher extent in $\mathrm{MH}$ - than in $\mathrm{MH}+$ biopsies, being detectable in 37 out of 114 fibre profiles in $\mathrm{MH}-$ and 37 out of 166 in $\mathrm{MH}+$. So there is no indication that the $\mathrm{MH}$ mutations influence this variable. Dilated $\mathrm{T}$ tubules were very rarely seen in both sets of samples.

Lysosomes (Fig. 2H) and myeloid figures (Fig. 3E, F) are indicative of some structural breakdown and/or recovery from it. Lysosomes are a normal component of all cells. An increase in their frequency is indicative of autophagy presumably following some structural breakdown. Myeloid figures are constituted of several layers of membranes in various configurations and most probably derive from mitochondrial breakdown. They are a more extreme indication of mitochondrial damage/breakdown than the milder variations in cristae configurations described earlier. Both organelles were 
not detected in about half of the $\mathrm{MH}$ - and one third of the $\mathrm{MH}+$ biopsies and where present their frequency was quite variable. The ratio of individual counts versus number of fibres was higher in $\mathrm{MH}-(1.73)$ than $\mathrm{MH}+$ (1.23), even though the overall ratio in the latter case is driven higher by two older patients, one of whom (L24) had signs of other muscle problems.

Two unusual structures concentric laminated bodies which are rare and apparently not related to $\mathrm{MH}$ mutations and to mitochondria ${ }^{10}$ (Fig. 3G) and mitochondria with crystalline inclusions (Fig. 3H) were found only in few fibres of two different biopsies (one $\mathrm{MH}+$ and one $\mathrm{MH}-$ ).

\section{Discussion}

Past structural observations on human muscles mostly focused on ascertaining how muscle was affected during an anaesthetic triggered $\mathrm{MH}$ episode and defined the current concept of considerable muscle damage with massive breakdown of muscle architecture. However, structural observations are limited. ${ }^{14}$ Probands biopsied at least some months after the reaction and their relatives show few features of clinical relevance. Indeed, our extensive examination of $\mathrm{MH}$ biopsies does not reveal striking structural alterations that can be considered as uniquely resulting from long lasting negative effects of the mutation and/or from regeneration. At a subtle level the indication is that some continuous, if minor, problems exist. For example, contractures and $\mathrm{Z}$ line streaming have been directly linked to the micro damage induced by eccentric contractions ${ }^{15}$ and extensive contractures are present in MH susceptible swine, an early model for the disease. ${ }^{16}$ The higher incidence of these alterations in $\mathrm{MH}+$ than $\mathrm{MH}-$ muscles might indicate that either the $\mathrm{MH}+$ muscles are more susceptible to subliminal damage, or that some, mostly localized, foci of inappropriate calcium release may randomly develop in time, resulting in mini localized "episodes" that may not be revealed as clinically detectable symptoms. Indeed, $\mathrm{MH}$ clinicians are becoming increasingly aware that many MH susceptible patients, especially when directly questioned, report intermittent muscle pain and/or cramps. Furthermore, hypercontractility may underlie exertional myalgia and rhabdomyolysis associated with $R Y R 1$ variants. ${ }^{17}$ It is interesting that $\mathrm{Z}$ line streaming and to a more limited extent contractures, are a hallmark of structural alterations in mouse models of MH. ${ }^{18-20}$

Alterations in mitochondrial matrix density and cristae architecture, as well as some of the more dramatic but less frequent mitochondrial breakdowns are also indicative of changes that seem to be linked to $\mathrm{MH}$ mutations. These may not be sufficient to induce a strong functional deficit in muscles that rely on glycolysis but are nonetheless indicative of some chronic dysregulation. In this respect, calcium balance immediately comes to mind. $\mathrm{MH}$ research has entered a new era with the discovery that in addition to the dramatic response to halothane, the mutated RyR1 and/or the RyR1/DHR complex are linked to chronic dysregulation of calcium homeostasis via indirect effects of RyR1 calcium leaks, changes in calcium entry via excitation-coupled calcium entry (ECCE) and via the $\mathrm{Na} / \mathrm{Ca}$ exchanger. ${ }^{7,21,22}$ Normal RyR1 channels critically regulate $\left[\mathrm{Ca}^{2+}\right]$ rest in skeletal myotubes, but the regular balance is disrupted by the $\mathrm{MH}+$ mutations. $^{23}$

Interestingly mouse models of $\mathrm{MH}$ induced by the expression of identified RyR1 mutations ${ }^{18-20}$ have failed to induce changes in mitochondrial inner architecture, despite the continuously slightly elevated resting calcium. However, both human biopsies (this report), mouse models of $\mathrm{MH}{ }^{19}$ and longterm aging mice ${ }^{24}$ show convergent alterations in mitochondrial disposition indicative of increased fission and/or a loosening of the tethering connections that hold mitochondria in position, allowing them to move freely. The only mouse model that revealed striking structural alteration was linked to a central core RyR1 mutation (Y522S). None of the patients in this group carried that mutation.

\section{Author's contributions}

ML collected and analyzed EM data, wrote manuscript. PKG organized patients, collected biopsies edited manuscript. PMH identified mutations, directed clinical work, wrote manuscript. CFA analyzed data, wrote manuscript.

\section{Acknowledgments}

Supported by NIH grant 2PO1 AR 052354-06A1 to P.D. Allen (CFA \& PMH core leads). The content is solely the responsibility of the authors and does not necessarily represent the official views of the National Institutes of Health.

\section{Conflict of Interest}

The authors submit no conflict of interest regarding the publication of this article.

\section{Corresponding Author}

Manuela Lavorato, Department of Cell and Developmental Biology, University of Pennsylvania School of Medicine, B 42 Anatomy Chemistry Bldg. Philadelphia PA 19104-6058 USA

Phone 2158983345 Fax 2155732170

Email: lavman@mail.med.upenn.edu

\section{E-mails of coAuthors}

Pawan K Gupta: gpawank@gmail.com Philip M Hopkins: P.M.Hopkins@leeds.ac.uk Clara Franzini-Armstrong: armstroc@mail.med.upenn.edu

\section{References}

1 Galli L, Orrico A, Cozzolino S,et al. Mutations in the RYR1 gene in Italian patients at risk for 


\section{Skeletal muscle in Malignant Hyperthermia patients}

Eur J Transl Myol 26 (4): 323-332

malignant hyperthermia: Evidence for a cluster of novel mutations in the C-terminal region. Cell Calcium 2002;32:143-51.

2. Monnier N, Krivosic-Horber R, Payen J-F,et al. Presence of two different genetic traits in malignant hyperthermia families: Implication for genetic analysis, diagnosis, and incidence of malignant hyperthermia susceptibility. Anesthesiology 2002;97:1067-74.

3. Carpenter D, Ringrose C, Leo V, et al. The role of CACNA1S in predisposition to malignant hyperthermia. BMC Med Genet 2009; 10:10415.

4. Monnier N, Procaccio V, Stieglitz P, Lunardi J Malignant-hyperthermia susceptibility is associated with a mutation of the alpha 1 subunit of the human dihydropyridine-sensitive L-type voltage-dependent calcium-channel receptor in skeletal muscle. Am J Hum Genet 1997;60:1316-25.

5. Pirone A, Schredelseker J, Tuluc P, et al. Identification and functional characterization of malignant hyperthermia mutation $\mathrm{T} 1354 \mathrm{~S}$ in the outer pore of the Cava1S-subunit. Am J Physiol Cell Physiol 2010;299: C1345-54.

6. Eltit JM, Bannister RA, Moua O, et al. Malignant hyperthermia susceptibility arising from altered resting coupling between the skeletal muscle Ltype $\mathrm{Ca}^{+}$channel and the type 1 ryanodine receptor. Proc Natl Acad Sci USA 2012;109:7923-8.

7. Eltit JM, Ding X, Pessah IN, et al. Nonspecific sarcolemmal cation channels are critical for the pathogenesis of malignant hyperthermia. FASEB J 2013;27:991-1000.

8. Hopkins PM, Rüffert H, Snoeck MM, et al. European Malignant Hyperthermia Group. The European Malignant Hyperthermia Group guidelines for the investigation of malignant hyperthermia susceptibility. $\mathrm{Br} \mathrm{J}$ Anaesth 2015;115:531-9.

9. Fiszer D, Shaw M-A, Fisher NA, et al. Next generation sequencing of RYR1 and CACNA1S in malignant hyperthermia and exertional heat illness. Anesthesiology 2015:122;1033-46.

10. Engel AG, Banker BQ. Ultrastructural changes in diseased muscle. In Myology III Ed., AG Engel, C. Franzini-Armstrong eds. McGraw Hill NY 2004 pp 749-888.

11. Burke RE. The structure and function of motor units. In Myology. A,G Engel and C. FranziniArmstrong, eds, McGraw Hill, NY. 2004, pp.104-19.
12. Sharon RS. Human skeletal muscle fiber types: delineation, development, and distribution. Can J Appl Physiol 1997 22:307-27.

13. Hilber K, Galler S, Gohlsch B, Pette D. Kinetic properties of myosin chain isoforms in single fibers from human skeletal muscle. FEBS Lett 1999;455:267-70.

14. Schiller HH, Mair WGP. Ultrastructural changes of muscle in malignant hyperthermia. J Neurol Sci 1974;21:93-9.

15. Newham DJ, McPhail G, Mills KR, Edwards RHT. Ultrastructural changes after concentric and eccentric contractions of human muscle. J Neurol Sci 1983;61:109-22.

16. Palmer EG, Topel DG, Christian LL Microscopic observations of muscle from swine susceptible to malignat hyperthermia. J. Animal Sci 1977;45:1032-35.

17. Dlamini N, Voermans NC, Lillis $\mathrm{S}$, et al. Mutations in RYR1 are a common cause of exertional myalgia and rhabdomyolysis. Neuromuscul Disord 2013;23:540-8.

18. Boncompagni S, Rossi AE, Micaroni M, Characterization and temporal development of cores in a mouse model of malignant hyperthermia. Proc Natl Acad Sci USA 2009;106:21996-2001.

19. Boncompagni S, Loy RE, Dirksen RT, FranziniArmstrong C. The $14895 \mathrm{~T}$ mutation in the type 1 ryanodine receptor induces fiber-type specific alterations in skeletal muscle that mimic premature aging. Aging Cell 2010;9:958-70.

20. Yuen B, Boncompagni S, Feng W, et al. Mice expressing T4826I-RYR1 are viable but exhibit sex- and genotype-dependent susceptibility to malignant hyperthermia and muscle damage. FASEB J 2012;26:1311-22.

21. Yang $T$, Allen PD, Pessah IN, Lopez JR. Enhanced excitation-coupled calcium entry in myotubes is associated with expression of RyR1 malignant hyperthermia mutations. J Biol Chem. 2007;282:37471-78.

22. Altamirano F, Eltit JM, Robin G, et al. Ca2+ influx via the $\mathrm{Na}+\mathrm{Ca} 2+$ exchanger is enhanced in malignant hyperthermia skeletal muscle. J Biol Chem 2014;289:19180-90.

23. Eltit JM, Yang T, Li H, et al. RyR1-mediated $\mathrm{Ca} 2+$ leak and $\mathrm{Ca} 2+$ entry determine resting intracellular $\mathrm{Ca} 2+$ in skeletal myotubes. J Biol Chem 2010;285:13781-7.

24. Pietrangelo L, D'Incecco A, Ainbinder A, et al. Age-dependent uncoupling of mitochondria from $\mathrm{Ca} 2+$ release units in skeletal muscle Oncotarget 2015;6:35358-71. 